\title{
A Atuação do Psicólogo na Estratégia Saúde da Família: Articulações Teóricas e Práticas do Olhar Gestáltico*
}

\author{
Juliana Diógenes \\ Universidade Federal do Ceará, CE, Brasil.
}

\author{
Ricardo José Soares Pontes \\ Universidade Federal do Ceará, CE, Brasil.
}

\begin{abstract}
Resumo: Este trabalho emerge de interrogações da pesquisadora durante desenvolvimento profissional, a partir da experiência em Gestalt-terapia e Residência Multiprofissional em Saúde da Família e Comunidade. Com conhecimento teórico e prático em ambas as áreas, propõe a construção de pontes teórico-conceituais entre elas, mostrando contribuições possíveis da Gestaltterapia para o trabalho do psicólogo no contexto da Estratégia Saúde da Família (ESF), bem como à sua principal ferramenta de processo de trabalho, a Clínica Ampliada (CA). Trata-se de pesquisa qualitativa, com amostra intencional de psicólogos que trabalham na ESF do Ceará. Realizadas entrevistas individuais, o material empírico foi categorizado em cinco temas: importância das abordagens psicológicas para a atuação do psicólogo na ESF; visões de homem das abordagens humanistas norteadoras da atuação do psicólogo na ESF; valorização pelos psicólogos do modo de vida dos sujeitos e suas demandas; modos de intervenção do psicólogo na ESF; conexões teóricas e práticas. Em síntese, os resultados indicaram: a Gestalt-terapia tem aceitação dos psicólogos que trabalham na ESF; e a principal contribuição da abordagem para esse cenário é a visão de totalidade do ser humano, já que é exigência da ESF e da CA trabalhar com visão integrada de um sujeito singular, compreendido num contexto amplo. Conclui-se que, quando a abordagem psicológica possui visão de homem que se aproxima das diretrizes da ESF e o psicólogo consegue unir ambas as formações na sua prática, uma garantia de atuação qualificada neste contexto é facilitada.

Palavras-chave: Gestalt-terapia, Estratégia Saúde da Família, Clínica Ampliada.
\end{abstract}

\section{The Performance of the Psychologist in the Family Health Strategy: Combining Theory and Gestalt-Oriented Practices}

\begin{abstract}
This work comes from the researcher's questions developed in her professional career, from the experience in Gestalt-Therapy (GT) and Multidisciplinary Residency in Family Health and Community. With theoretical and practical knowledge in both areas, proposes the construction of theoretical and conceptual bridges between them, with the objective of showing possible contributions that GT can offer to the work of the psychologist in the context of Family Health Strategy (FHS), as well as to its main work process tool, Extended Clinic (EC). It is qualitative research, with purposive sample of psychologists of the Residence Integrated Health with Emphasis on Health Family and Community, of the Public Health School of Ceará. With the execution of individual interviews, the empirical material was categorized in five themes: importance of the psychological approaches for the performance of the psychologist at FHS; views of man and world of the humanitarian approaches while guiding the performance of the psychologist at
\end{abstract}

*Este trabalho é produto de dissertação de Mestrado em Saúde Pública, pela Universidade Federal do Ceará. Emerge de interrogações da pesquisadora desenvolvidas na sua carreira profissional, a partir da experiência em Gestalt-terapia (GT) e Residência Multiprofissional em Saúde da Família e Comunidade. 
FHS; appreciation by psychologists of the way of life of subjects and their demands; intervention methods of the psychologist at FHS; and theoretical and practical connections. In summary, the results indicated that: GT has acceptance and use by the psychologists who work at FHS; and the approach's main contribution to that scenario is the view of totality of the human being, since it is required of FHS and EC to work with an integrated view of a singular subject, which should be understood in a broad context. In conclusion, when the psychological approach has a view of man closer to the guidelines of FHS, and the psychologist can combine both formations in their practice, an assurance of qualified performance in this context is promoted.

Keywords: Gestalt-Therapy, Family Health Strategy, Extended Clinic.

\title{
La Actuación del Psicólogo en la Estrategia de Salud de la Familia: Teoría y Prácticas de Visión Gestáltica en Conjunto
}

\begin{abstract}
Resumen: Este trabajo es producto de las preguntas desarrolladas por la investigadora en su ejercicio profesional, relacionado tanto con su experiencia con la Terapia Gestalt (GT) como con su Residencia Multidisciplinaria en Salud Familiar y Comunitaria. A partir del conocimiento de la teoría y la práctica en las dos áreas, la investigadora propone la construcción de puentes teóricosconceptuales entre ellas, con el fin de mostrar las posibles contribuciones que la GT puede ofrecer al trabajo del psicólogo en el contexto de la Estrategia de Salud de la Familia (ESF), así como a la principal herramienta de esa estrategia: la Clínica Ampliada (CA). Se trata de una investigación cualitativa con una muestra por conveniencia de psicólogos provenientes de la Residencia Integrada de Salud con Énfasis en Salud de la Familia, de la Escuela de Salud Pública del Ceará. Con la realización de entrevistas individuales, el material empírico se clasificó en cinco temas: importancia de los enfoques psicológicos para el ejercicio del psicólogo en la ESF; comprensión del hombre y del mundo de los enfoques humanistas en el desempeño del psicólogo en la ESF; valoración por los psicólogos del modo de vida de los sujetos y de sus demandas; métodos de intervención del psicólogo en la ESF; y, conexiones teóricas y prácticas. En resumen, los resultados indicaron que: la GT cuenta con aceptación y uso por parte de los psicólogos que trabajan en la ESF; y, la principal contribución del enfoque para ese escenario es su visión integral del ser humano, ya que es necesario que la ESF y la CA trabajen con una visión integradora de un sujeto singular, entendido en un contexto amplio. Se llega a la conclusión de que cuando el enfoque psicológico tiene una visión del hombre que se acerca de las directrices de la ESF, y cuando el psicólogo puede unir ambas esferas en su práctica, se garantiza un desempeño de calidad en este contexto.

Palabras clave: Terapia Gestalt, Estrategia Salud de la Família, Clínica Ampliada.
\end{abstract}

\section{Introdução}

O Sistema Único de Saúde (SUS), no Brasil, em sua concepção e práticas, vem desafiando os trabalhadores do campo da saúde a concretizar os princípios doutrinários da Reforma Sanitária inscritos na Constituição Federal, por meio de processos cotidianos de trabalho nos serviços públicos-assistenciais, constituindo-se, assim, em práxis permanente e inovadora que continuamente incorpora novos atores com formações profissionais diversificadas. Essa concretização implica nos desafios de inclusão e articulação de novos paradigmas e modos de cuidar da saúde individual e coletiva da população brasileira. Tal desafio é colocado particularmente à Psicologia e às outras profissões que foram chamadas mais recentemente a contribuir com o SUS, especialmente atuando na Estratégia Saúde da Família (ESF) (Conselho Federal de Psicologia, 2009). 
A predominância do modelo biomédico na formação e educação nos cursos de graduação em saúde e afins, incluindo em vários aspectos a Psicologia, impõe a necessidade de transformações na capacitação dos profissionais, que enfatize as concepções ampliadas de saúde, ações interdisciplinares e intersetoriais, valorizando a participação social e a cidadania nos processos de produção da saúde e do cuidado (Ceccim, \& Feuerwerker, 2004; Ceccim, 2005; Gil, 2005; Conselho Federal de Psicologia, 2009). Para o Conselho Federal de Psicologia: "Diante de um novo paradigma de saúde, mais ampliado e complexo, há a necessidade de criar novos modos de atuar, novos pontos de vista, novos campos e cenários" (Conselho Federal de Psicologia, 2009, pp. 51-52). E, no âmbito da ESF, é preciso criar, desenvolver e fortalecer modelos de atuação que possam trabalhar efetivamente com os determinantes psicossociais da saúde e da doença. Assim, as abordagens psicológicas, embora tenham sua origem no campo da Psicologia Clínica, atualmente já são utilizadas nos mais diversos contextos de atuação da Psicologia, inclusive nas práticas da saúde pública, como é o caso da Estratégia Saúde da Família (Bastos, \& Gomide, 1989).

O psicólogo inserido no cenário da ESF contribui essencialmente para a ampliação do olhar sobre o território, a comunidade e a escuta qualificada das pessoas. Em seu fazer, fortalece vínculos e contribui com a (re)construção dos processos de vida comunitários. Promove o diálogo nas suas diversas dimensões e possibilidades de práticas, voltando-se para o cuidado à família e à comunidade, entendendo-as como uma rede complexa formada através da interligação das diversas relações e demandas reais existentes (Camargo-Borges, \& Cardoso, 2005; Ronzani, \& Rodrigues, 2006). Em decorrência do perfil da demanda que chega para o psicólogo na ESF ser caracterizada por excessiva diversidade de pessoas e problemas, requisita-se desse profissional habilidade teórica e metodológica para dar conta dos fenômenos que surgem e necessitam ser trabalhados, na perspectiva psicológica, enquanto campo de saberes e práticas. Exige-se do psicólogo uma diversidade de instrumentos teóricos e metodológicos que proporcione uma atuação qualificada. (Pretto, Langaro, \& Santo, 2009; Nepomuceno, \& Brandão, 2011).

Particularmente, entre outras formações psicológicas que promovem importantes contribuições na requalificação paradigmática do cuidado no contexto da
ESF, a Gestalt-terapia (GT) parece atender a inúmeros desses requisitos, por dispor de diversos instrumentos teórico-metodológicos compatíveis com os princípios e práticas preconizados pelo SUS. Portanto, o objetivo desse estudo, realizado por meio de pesquisa qualitativa sobre a prática de psicólogos inseridos na ESF, é compreender como a GT pode contribuir para o trabalho do psicólogo na ESF e para a requalificação do cuidado, ao articular seus saberes e práticas específicos com aqueles instituídos no Sistema Único de Saúde por meio da ESF, bem como com uma de suas importantes ferramentas de processo de trabalho, representada pelo dispositivo da Clínica Ampliada (CA).

\section{Referenciais teóricos e metodológicos da Gestalt-terapia (GT) e da Estratégia Saúde da Família (ESF)/Clínica Ampliada (CA)}

Algumas anotações conceituais sobre a Gestalt-terapia (GT). Ao inserir esse contexto numa visão gestáltica, é essencial oferecer uma noção do que é GT. A palavra gestalt, de origem alemã, se refere a forma ou configuração, modo peculiar de organização de partes individuais que compõem um todo. Este conceito se fundamenta na visão holística de homem proposta pela GT, propondo que o ser humano deve ser percebido como um todo constituído pela interdependência de suas partes (D'acri, Lima, \& Orgler, 2007; Ribeiro, 2006). Dessa forma, pode-se pensar que a pessoa é uma gestalt, assim como a família é uma gestalt em si e também parte da gestalt comunidade. Nesse sentido, o conceito de campo se torna fundamental para uma compreensão ainda mais ampla da totalidade. O campo é o meio, o espaço de vida da pessoa. O comportamento das pessoas recebe influência direta da soma dos fatos que ocorrem dentro deste campo, ou seja, comportamento é uma função da relação da pessoa com seu meio, ou relação de campo -organismo-meio. Todas as dimensões pelas quais o campo da pessoa se constitui interferem em seu desenvolvimento.

Para a GT, qualquer que seja o acontecimento ocorrerá dentro de um campo espaço/temporal, onde diversas forças agem simultaneamente, de modo que constroem a realidade do momento atual. É nesse campo que o ser humano vai se constituindo e se encontra inteiro (Ribeiro, 2006): "A pessoa pode ser representada esquematicamente como um campo - por exemplo, um círculo - dentro de outro campo maior, 
que é o seu espaço de vida, onde psicologicamente podem ocorrer situações que a influenciam" (Orgler, Lima, \& D’Acri, 2007, p. 210).

Nele, encontramos variáveis de maior ou menor importância para a pessoa que, baseada nas suas vivências, necessidades e motivações, vão se ajustando criativamente dentro da sua realidade e desencadeando um funcionamento saudável ou não. Dessa forma, saúde e doença são partes do mesmo processo de ajustamento criativo daquela pessoa, o qual se fundamenta no processo homeostático que, por sua vez, está sempre se reconfigurando de acordo com as necessidades e interesses da pessoa e se dá por meio da formação de figura e fundo, que formam uma gestalt.

A figura é a necessidade emergente que, por ser a mais importante no momento, surge antes de outras necessidades, as quais ficam num segundo plano - o fundo. Neste estão todas as outras questões que precisam ser satisfeitas, mas que cederam lugar para a necessidade dominante naquele momento. Só quando esta figura emerge e assim torna-se (re)conhecida, ocorrerá a satisfação da necessidade, ou seja, a dissolução da figura, e assim, o surgimento de outra. Vale ressaltar que a figura não está isolada do fundo, ela existe no fundo, o qual, por sua vez, revela a figura e permite seu surgimento (Perls, 1981a).

Sendo a pessoa um ser de relação, o ajustamento criativo se dá a partir da satisfação de necessidades e da sua capacidade de adaptação ou de se autorregular às situações que ocorrem dentro da relação que ela tem consigo, com o outro e com seu meio. Assim, doença também pode ser considerada como uma forma pela qual as pessoas se ajustam dentro da sua realidade, pois acontece dentro de um processo, tem um sentido, ou seja, é um dos caminhos para a construção de uma vida, o significado que é dado às suas experiências: saúde e doença em Gestalt-terapia são concebidos não como "estados", mas como "processos" que favorecem ou dificultam o desenvolvimento da pessoa (D’Acri, Lima, \& Orgler, 2007, p. 71).

De acordo com Perls (1981b), a doença pode ser considerada como um distúrbio no processo vital do ser humano perante uma situação que o coloca de alguma forma em risco. Já a saúde, o autor define como um equilíbrio adequado da coordenação de tudo o que somos. E ressalta que saúde e doença não são algo que o ser humano tem, o ser humano é a própria saú- de e/ou a própria doença, que se manifestam na sua totalidade existencial:

“'Saúde' e 'doença', ou 'funcionamento saudável' e 'não saudável', são pensados dialeticamente, uma vez que o mesmo comportamento pode ser saudável ou não, dependendo de “'a serviço do que' ele está” (D’Acri, Lima, \& Orgler, 2007, p. 72).

Em GT, o funcionamento saudável se caracteriza como a capacidade humana de criar e recriar constantemente novas formas de atender à necessidade emergente, e de destruir formas disfuncionais, reconfigurando-as de acordo com a situação. O funcionamento não saudável se caracteriza por interrupções, inibições e obstruções destes processos de satisfação de necessidades, com a consequente formação de figuras confusas, que ao não se completarem fecham as possibilidades de contato com o presente. Assim, doença pode ser entendida como a recorrência crônica do funcionamento não saudável, deixando o indivíduo com suas dificuldades cristalizadas e seus contatos com o meio empobrecidos.

Outro conceito importante da GT a ser enfatizado é o processo de constante conscientização (awareness), que leva a pessoa a entrar em contato pleno com suas necessidades. A pessoa, ou mesmo a família, ou ainda a comunidade precisa estar consciente para que possa se responsabilizar pelo seu "estar-sendo". A partir do reconhecimento e conscientização de sua realidade, 0 sujeito (individual ou coletivo), vai estabelecendo suporte para fazer algo com aquilo que foi conscientizado. Assim, a awareness está diretamente ligada à realidade da situação e à forma como o sujeito se encontra, se percebe e se responsabiliza.

Em GT, os processos de vida trazidos pela pessoa naquele momento são constituídos de vivências passadas, expectativas futuras, e de significados e percepções construídas no seu contexto atual. Para que o psicólogo possa ter uma compreensão mais profunda tanto de uma pessoa como de uma família ou uma comunidade, é essencial que construa vínculos. A relação dialógica, base metodológica da abordagem gestáltica, facilita a construção desses vínculos, pois permite que o psicólogo se coloque inteiro na sua relação com o sujeito, percebendo-o como um todo, um ser integral.

Algumas anotações conceituais sobre a Estratégia Saúde da Família (ESF)/Clínica Ampliada (CA). A Integralidade constitui-se uma das principais diretrizes da ESF, baseada na compreensão de sujeitos, 
considerados individuais ou coletivos, a partir de uma visão ampliada do conceito de saúde, suficientemente aberta para considerar as várias dimensões que compõem o processo saúde-doença.

Uma das ferramentas do processo de trabalho mais utilizadas no cenário da ESF, de acordo com Cunha e Campos (2009), é a Clínica Ampliada, que visa à construção de uma síntese entre a clínica individualizante, a saúde pública e a gestão, respeitando cada saber técnico de caráter profissional em sua gênese formativa e o saber popular (Andrade, Barreto, \& Bezerra, 2009).

A fundamentação da Clínica Ampliada baseia-se no conceito de um sujeito coproduzido dialeticamente pelo tensionamento permanente entre forças internas (desequilíbrio orgânico e suporte emocional, por exemplo), que caracterizam seu elemento particular, e externas (situação sócio-econômico-cultural, por exemplo), que caracterizam seu elemento universal (Cunha, 2010).

De acordo com Campos (2009), o sujeito singular, como já citado, se constitui através dos tensionamentos simultâneos que recebe de suas forças internas e externas, sendo essa interação entre forças forte influência no funcionamento saudável ou não do sujeito. A dor sentida por ele é única, ninguém mais a sente do mesmo modo, pois esse sujeito é singular, e apenas ele poderá escolher por qual caminho irá se ajustar: "Doenças físicas e mentais são, muitas vezes, formas desesperadas de ajustamento criativo, como uma linguagem que, por meio da dor, consegue se fazer ouvir, pois o intelecto já não encontra resposta adequada a suas demandas" (Ribeiro, 2006. p. 65)

Saúde e doença fazem parte do mesmo processo de crescimento e transformação durante toda a vida de uma pessoa, favorecendo ou dificultando seu desenvolvimento, uma vez que satisfazendo ou não as necessidades que vão emergindo da sua realidade, contribuem para um funcionamento saudável ou não. (D’Acri, Lima, \& Orgler, 2007). De acordo com Santos e Rigotto (2010), o processo saúde-doença é construído dentro do território, a partir da interligação de todas as suas dimensões (socioeconômicas, histórico-culturais, ambientais, psicológicas, políticas, biológicas, epidemiológicas, individuais etc.). O território possui aspectos inerentes ou mesmo construídos pelo homem que caracterizam o ambiente, o qual interfere no processo saúde-doença da população, dá-se no cotidiano vivido, está em permanente construção, é dinâmico, gera transformações nas pessoas. Ou seja, é o lu- gar onde a vida da comunidade acontece, onde as pessoas se transformam e são transformadas. Num mesmo território, podem haver várias comunidades (Góis, 2005; 2008).

A comunidade potencializa o sentimento de pertença das pessoas, a participação na mesma cultura e vinculação a um território comum, é um espaço de moradia e convivência direta e duradoura, onde os moradores possuem um nível socioeconômico semelhante, laço histórico comum, as mesmas necessidades e problemas sociais e um sistema próprio de representações sociais (Góis, 2005; 2008). Na proposta de Campos (2009), saúde e doença podem ser vistas como fenômenos sociais constituídos a partir de uma multiplicidade de fatores externos e internos aos sujeitos, que são interdependentes e vão interagir constantemente, desencadeando um processo de conscientização. Nesse movimento, o sujeito tem a possibilidade de se perceber também responsável pela própria saúde e pela própria doença, o que remete ao conceito da corresponsabilização, o qual se refere ao "esforço simultâneo para aumentar o coeficiente de autonomia e autocuidado dos pacientes, famílias e comunidades" (Andrade et al., 2009, p. 818). Corresponsabilização e vínculo são importantes ações que as categorias profissionais, incluindo a Psicologia, assumem no contexto da ESF.

\section{Método}

\section{Referencial teórico-metodológico e técnica de coleta e análise de dados}

A investigação afiliou-se ao referencial teórico-metodológico da pesquisa qualitativa em saúde, que trabalha com a dimensão vivencial e narrativa de fenômenos singulares, buscando compreender e explicar as relações particulares dentro de seu processo dinâmico, abordando um nível da realidade que não tem como ser quantificado. Investiga relações, grupos ou segmentos delimitados, a história social a partir da visão dos seus atores, revela processos sociais ainda pouco conhecidos de grupos particulares, e colabora com a construção de novas abordagens (Minayo, 2010;, 2012).

$\mathrm{Na}$ análise e discussão dos resultados, foi utilizada a vertente fenomenológica-hermenêutica, em uma perspectiva crítico-dialética, de narrativas orais (Minayo, 2012), entendendo que essa proposição propicia contribuições não só ao como fazer, mas 
também ao como pensar a análise do material empírico em pesquisas na área da saúde. A fenomenologia hermenêutica procura levar em conta dimensões como o contexto dos atores investigados; a existência de racionalidade e responsabilidade nas diversas linguagens e formas de comunicação; a contextualização dos fatos e observações na realidade dos atores; e a produção de relatos em que os atores se percebam contemplados. Já a perspectiva dialética, é vista por Minayo (2012), como "a arte do estranhamento e da crítica” (p. 337), o que permite fazer articulações com a fenomenologia-hermenêutica, uma vez que esta última "caminhando entre aquilo que é familiar e o que é estranho, busca esclarecer as condições sob as quais surge a fala" (Minayo, 2012, p. 99).

Na pesquisa de campo, foi utilizada a entrevista individual aberta. Os participantes foram selecionados intencionalmente entre os psicólogos com atuação na Estratégia de Saúde da Família. O tamanho da amostra foi definido por meio da saturação teórico-empírica dos relatos, bem como da relevância das informações e observações que ofereceram contribuições significativas e adequadas ao delineamento do objeto em apreensão. Dessa forma, foram entrevistados 12 psicólogos, Gestalt-terapeutas ou não, que trabalham na ESF do Estado do Ceará.

Os procedimentos éticos foram orientados pelo Conselho Nacional de Saúde que, por meio da Resolução no 196/96, oferece as diretrizes para a realização de pesquisas com seres humanos. Foi inscrito na Plataforma Brasil submetido ao Comitê de Ética em Pesquisa da Universidade Federal do Ceará e aprovado pelo Parecer $n^{\circ}$ 562.662. Com o intuito de garantir o sigilo dos entrevistados, as entrevistas foram enumeradas de 1 a 12, e representadas apenas pela letra "E".

\section{Categorias empíricas de análise}

Analisado o material discursivo, foram identificadas duas importantes dimensões surgidas através de leitura flutuante e exaustiva do material. A primeira dimensão é a divisão dos psicólogos em dois grandes grupos: (A) aqueles que se identificam ou seguem a linha da GT ou das abordagens humanistas e (B) aqueles que não se identificam ou não seguem a linha da GT ou das abordagens humanistas. Estas últimas aproximam-se entre elas em suas bases teóricas e visões de mundo: Abordagem Centrada na Pessoa (ACP), a própria GT, dentre outras.

Pelo fato de a GT ser o referencial teórico deste trabalho, ela foi destacada separadamente das abordagens humanistas. Sendo assim, no grupo A, temos uma subdivisão em duas categorias: (A.I) aqueles que trabalham norteados pela GT, e (A.II) aqueles que trabalham a partir de outra abordagem humanista, ambos com quatro entrevistados. No grupo B, a subdivisão em categorias se dá da seguinte forma: (B.I): aqueles que partem de um olhar psicossocial, a Psicologia Comunitária, a Psicologia Social, a abordagem sócio-histórica, com três entrevistados, e (B.II): aqueles que trabalham com base na Psicanálise ou na Psicologia Comportamental, com um entrevistado.

A segunda dimensão se relaciona ao material empírico, cujas entrevistas foram organizadas em cinco temas: a importância das abordagens psicológicas, de uma forma geral, para a atuação do psicólogo na ESF; as visões de homem e de mundo das abordagens humanistas enquanto norteadoras da atuação do psicólogo na ESF; a valorização pelos psicólogos do modo de vida dos sujeitos (individuais ou coletivos) e das demandas demonstradas por estes; os modos de intervenção do psicólogo no contexto da ESF; as conexões teóricas e práticas (Tabela).

Tabela

Conexões teóricas e práticas entre a GT e o trabalho do psicólogo na ESF.

\begin{tabular}{|c|c|c|c|c|c|}
\hline Totalidade & Campo & Figura e fundo & Ajustamento criativo & Relação dialógica & Awareness \\
\hline Integralidade & $\begin{array}{l}\text { Comunidade e } \\
\text { território }\end{array}$ & $\begin{array}{l}\text { Necessidades } \\
\text { sociais e de } \\
\text { saúde }\end{array}$ & $\begin{array}{c}\text { Processo saúde- } \\
\text { doença }\end{array}$ & Vínculo & Conscientização \\
\hline $\begin{array}{l}\text { Visão de } \\
\text { homem e de } \\
\text { mundo }\end{array}$ & $\begin{array}{c}\text { Visão de homem } \\
\text { e de mundo } \\
\text { Valorização do } \\
\text { modo de vida e } \\
\text { das demandas } \\
\text { dos sujeitos }\end{array}$ & $\begin{array}{l}\text { Valorização } \\
\text { do modo de } \\
\text { vida e das } \\
\text { demandas dos } \\
\text { sujeitos }\end{array}$ & $\begin{array}{c}\text { Valorização do } \\
\text { modo de vida e } \\
\text { das demandas dos } \\
\text { sujeitos }\end{array}$ & $\begin{array}{c}\text { Modos de } \\
\text { intervenção }\end{array}$ & $\begin{array}{c}\text { Modos de } \\
\text { intervenção }\end{array}$ \\
\hline
\end{tabular}


Na Tabela, é possível observar que três dos temas empíricos estão associados a mais de um conceito teórico, e que os outros dois temas não estão associados especificamente a nenhum conceito. Isso significa que essa separação e associação são apenas um modo de facilitar a compreensão do estudo e das conexões existentes entre eles, mas que todos estão interligados e se influenciam.

\section{Resultados e discussão}

\section{A importância das abordagens psicológicas para a atuação do psicólogo na ESF}

As diversas abordagens psicológicas, cada uma com suas características no campo paradigmático próprio, podem oferecer importantes contribuições ao trabalho do psicólogo na ESF, através do suporte teórico que elas fornecem para este profissional, tornando-as de fundamental importância nesse contexto, inclusive diferenciando-o de outras profissões da saúde:

\begin{abstract}
A gente precisa de uma fundamentação. É o que diferencia o psicólogo de outro profissional, enquanto alguém que faz uma escuta qualificada, porque qualquer profissional de saúde pode fazer, mas eu acho que o que diferencia a nossa escuta qualificada, o contato com o outro, o estabelecimento do vínculo é exatamente esse embasamento teórico que a gente adquire. Então, elas são importantes sim. (E10)
\end{abstract}

São as abordagens psicológicas, por meio das suas fundamentações teóricas, que vão diferenciar a atuação do psicólogo com a das outras categorias profissionais, pois são essas abordagens que trazem conceitos e modos de ver o homem e o mundo, que norteiam aspectos fundamentais para uma prática interventiva de qualidade, tais como, o tipo de relação a ser estabelecido com o sujeito e, consequentemente, a profundidade do vínculo, as técnicas a serem utilizadas com esse sujeito, bem como o modo de acompanhá-lo (Cordioli, 1998).

Outro aspecto relevante da atuação do psicólogo refere-se ao fato de que o profissional deve saber se utilizar das abordagens psicológicas de modo adequado, singular a cada situação e sujeito, uma vez que, no contexto da ESF, existe uma grande diversidade de situações e demandas:

Eu acho que seria trabalhar as teorias de uma forma contextualizada dentro da comunidade (E12).
Na verdade, não são as abordagens, são as pessoas, $o$ próprio psicólogo que limita sua visão, ou a visão que a abordagem traz, no contexto teórico (E7).

De acordo com Pedrassoli (2008), os psicólogos de uma determinada abordagem teórica, podem e devem fazer uso de técnicas originárias de outras correntes, sempre partindo da necessidade daquele sujeito que se põe à sua frente. Desse modo, caminha em busca de melhores resultados na atuação profissional, já que o mais importante é o desenvolvimento emocional e psicológico desse sujeito, de maneira saudável. Ou seja, o fato de se nortear por uma abordagem não significa que as outras deverão ser excluídas ou rejeitadas. Se o foco principal é a necessidade do sujeito, então o psicólogo, dentro de certos limites tanto em relação aos fundamentos teóricos como das possibilidades impostas pelas práticas da ESF, deve se utilizar de instrumentos que se adequem a cada situação particular.

A visão de mundo e de homem defendida por cada abordagem é o aspecto de base que irá nortear o modo de atuação do profissional, as técnicas utilizadas por ele, a forma como elas serão utilizadas, o modo do psicólogo desenvolver o vínculo com o sujeito, relacionar-se com ele e acompanhá-lo (Cordioli, 1998).

\section{As visões de homem e de mundo das abordagens humanistas enquanto norteadoras da atuação do psicólogo na ESF}

A visão de mundo trazida pelo psicólogo para seu contexto de trabalho influencia fortemente no seu modo de atuação profissional, ou seja, a forma como realiza o trabalho e sua postura diante das pessoas e das situações, diz muito da abordagem que escolheu:

\footnotetext{
A priori eu acho que a gente já se utiliza de uma abordagem, tendo ela não como um instrumento de trabalho, mas como uma visão de mundo. A abordagem influencia no método de trabalho, com certeza, porque tem a ver com a minha visão de mundo, e eu trabalho com a minha visão de mundo (E3).
}

O fato de a maior parte dos sujeitos entrevistados serem adeptos ou se identificarem com a GT, ou com as abordagens humanistas, pode ser um indicativo de que essas teorias podem contribuir com as práticas profissionais no contexto da ESF, uma vez que trazem 
uma proposta de visão de homem e de mundo que se aproxima intimamente da integralidade que a ESF tanto propõe.

Um psicólogo conseguirá compreender que, no contexto da ESF, os sujeitos devem ser considerados a partir de uma visão ampliada de saúde, em que devem ser levadas em conta todas as suas dimensões em decorrência de estarem interligadas e influenciando o processo saúde-doença desses sujeitos, se ele se identificar com essa visão de homem e de mundo:

Se a abordagem que eu acredito, que tem a ver com essa visão do mundo é quem fundamenta não só a minha atuação profissional, mas a minha própria existência, eu vou me identificar ou não com determinado contexto de trabalho, que aí eu acho que a Saúde da Família se aproxima mais realmente das humanistas e mesmo da própria Gestalt (E3).

Eu vejo que a questão da gente trabalhar o sujeito como um todo, de você não fragmentar aquele sujeito, mas ver ele numa totalidade, que eu acho que isso a Gestalt traz como uma das maiores contribuições (E4).

Pensar numa clínica ampliada é pensar na pessoa todinha. Tenho para mim que a abordagem humanista me favorece acessar essa pessoa todinha (E3).

Percebe-se que a GT traz, como uma de suas contribuições para a atuação do psicólogo na ESF, a visão de totalidade do ser humano, uma vez que, de acordo com Ribeiro (2006), essa abordagem propõe a compreensão do sujeito enquanto um ser que é formado por diversas dimensões, que são interdependentes, formam um todo significativo e influenciam seu funcionamento saudável (ou não).

Dessa forma, é possível pensar a relação de articulação entre o conceito de Totalidade proposto pela GT e o conceito de Integralidade, enquanto diretriz da ESF, que considera as várias dimensões do processo saúde-doença de indivíduos e coletivos, para que sejam compreendidos de forma integral, além da articulação do conceito de Sujeito Singular, trazido como embasamento para se pensar a Clínica Ampliada, onde, conforme Cunha (2010), esse sujeito é singular na medida em que é produzido a partir da tensão e encontro entre as suas forças internas e externas de seu contexto.

No que se refere às dimensões relacionadas às forças internas e externas (Cunha, 2010), podemos re- tomar os conceitos de comunidade e território. Este último é constituído pelos seus moradores, estabelecimentos e instituições ali construídos (igrejas, escolas, associações, fábricas, praças, unidades de saúde, etc), e também pelo significado que seus moradores dão a esse território. Já a comunidade é constituída basicamente pelas pessoas e pelos costumes e laços que elas vão construindo entre si (Góis, 2005).

Portanto, voltar-se para as necessidades do sujeito é dar abertura para novas possibilidades de atenção à sua saúde. Aqui, nos deparamos com outra contribuição possível da GT, já que sua visão de totalidade oferecida dá essa abertura, pois compreender o sujeito como um todo é estar atento ao seu campo e às suas necessidades, e assim facilitar a conscientização e satisfação delas.

\section{A valorização pelos psicólogos do modo de vida dos sujeitos (individuais ou coletivos) e das demandas demonstradas por estes}

Escutar a demanda de um sujeito ou observar o modo de funcionar e os movimentos de uma comunidade significa compreender esses sujeitos enquanto singulares, na sua integralidade, como uma totalidade:

No meu município, tem uma demanda muito grande com pessoas com ansiedade, e aí estou tentando montar um grupo agora... são pessoas que estão ociosas, ou porque trabalharam muito tempo e aí pararam para cuidar da casa, ou simplesmente nunca trabalharam fora mesmo, só cuidando da casa. Lá, não oferta um lazer, ou outra atividade para que eles possam estar participando (E11).

Alternativamente à medicalização biomédica e farmacológica usual na ESF, o grupo terapêutico, à luz da GT, oferece suporte, compreensão, amor, companheirismo, respeito, e funciona como uma escola da vida, em que as lições se dão de acordo com a capacidade de percepção de cada um de seus membros (Ribeiro, 2012), contribuindo para o desenvolvimento saudável não apenas das pessoas e do grupo, mas também da comunidade em que estão inseridos:

\footnotetext{
Não se pode dizer que existe um grupo só porque as pessoas foram colocadas juntas em algum lugar. Todo grupo é um sistema único com um caráter próprio e especial e uma noção peculiar da própria força; um conglomerado de energias emanadas por
} 
seus membros individuais, inter-relacionadas num padrão sistemático. É um todo, uma entidade, uma Gestalt cuja natureza é maior do que a soma de suas várias partes (Zinker, 2007, p. 178).

Ao trabalhar em grupo, o psicólogo está atento tanto às necessidades de indivíduos quanto do coletivo. Dessa forma, ao perceber que a ansiedade é uma figura emergente naquela comunidade, um meio para tentar diminuir os sintomas ansiosos é a formação de um grupo, onde dentro dele poderá trabalhar as figuras (necessidades) mais específicas de cada participante e do grupo como um todo, indo em busca do seu funcionamento saudável, por meio da facilitação da autorregulação organísmica:

Em sua melhor forma, é não só uma pequena comunidade coesa, na qual as pessoas se sentem recebidas, aceitas ou desafiadas, mas também um lugar e uma atmosfera em que elas podem se tornar criativas juntas. O grupo ideal é um local para cada pessoa testar seus limites de crescimento, uma comunidade em que os componentes podem desenvolver ao máximo seu potencial humano (Zinker, 2007, p. 177).

Assim, pode-se pensar o grupo enquanto espaço gerador de vida onde cada um dos seus participantes realiza em si o ato de se reorganizar e reencontrar. É um espaço onde se forma um núcleo de saúde que proporciona uma sucessão de mudanças intrapessoais, interpessoais e intergrupal (Ribeiro, 2012). Dessa forma, percebe-se a importância dos trabalhos de grupo para uma comunidade, pois o grupo é um momento onde as pessoas têm a oportunidade de perceber quais suas possibilidades de se ajustar criativamente ao seu contexto de vida, ao seu processo saúde-doença. Sempre que o organismo sente qualquer tipo de necessidade vai em busca, no meio, de algo que a satisfaça.

À medida que as necessidades do grupo vão sendo satisfeitas (se tornando fundo), outras figuras vão emergindo para que sejam trabalhadas e também satisfeitas, constituindo um ciclo de funcionamento saudável das pessoas e do próprio grupo. O psicólogo, estando atento ao processo saúde-doença dos sujeitos que acompanha e às suas demandas, pode facilitar o desenvolvimento de seu funcionamento saudável. Nesse sentido, partindo do princípio de que as pessoas podem ter um funcionamento saudável mesmo com alguns problemas de saúde, é possível pensar que saúde também está relacionada à forma como o sujeito se ajusta, ou lida com as coisas que lhe acontecem, à forma como percebe os fatos e satisfaz suas necessidades (Kiyan, 2001).

\section{Modos de intervenção do psicólogo no contexto da ESF}

As diretrizes para o contexto de atuação da ESF indicam que o profissional desenvolva vínculos com os moradores do território através da construção de relações de confiança e afeto, onde saberes e práticas devem se articular à construção de um processo de valorização da subjetividade, tornando os serviços de saúde mais acolhedores, para que a criação desses vínculos seja possível (Brasil, 2009).

A GT deixa o psicólogo livre e aberto para se relacionar com as pessoas com afetividade, acreditando que nessa relação mais próxima é onde estão embasadas as suas intervenções, com o intuito de facilitar o desenvolvimento de um funcionamento saudável dos sujeitos. Podemos perceber, assim, mais uma contribuição da abordagem gestáltica para o trabalho do psicólogo na ESF: "O que a gente tem observado também é esse contexto da relação terapêutica, que é também importante para Gestalt. Esse aqui e agora dessas relações que vão se estabelecendo" (E4).

A abordagem gestáltica propõe que a relação terapêutica seja formada a partir do diálogo e do contato entre duas pessoas. Contato é a própria relação, onde se constrói todo o caminho de desenvolvimento saudável do sujeito, pois é no contato que ele reconhece a si mesmo e a suas necessidades. O diálogo se constitui do contato e da relação gerada por ele, e assim nasce o que a GT reconhece como uma relação dialógica, onde as pessoas se vinculam no momento em que se contatam, pois a troca é compartilhada dentro da relação e aproxima as pessoas (Ribeiro, 2006)

Construída essa relação, de vínculo e afeto, o psicólogo tem a oportunidade de facilitar o processo de conscientização do sujeito, através do qual ele tem a possibilidade de dar-se conta de si mesmo, de suas necessidades, de seu contexto de vida. Assim, temos uma outra possibilidade de articulação de paradigmas entre a ESF, que propõe facilitar a conscientização e autonomia dos sujeitos (Brasil, 2009), e a GT, que enfatiza o processo de conscientização, chamado de awareness. A awareness leva o sujeito a entrar em contato pleno com suas necessidades, como se fosse uma consciência da consciência. Por meio da awareness, pessoa, família ou 
comunidade se tornam conscientes de si e de todo o seu campo (Yontef, 1998):

Especificamente falando da abordagem gestáltica, eu acho que a gente trabalha muito com essa vertente quando a gente propõe essa tomada de consciência desse momento que elas estão passando, a gente propõe também a questão das relações, que é muito privilegiada nesse grupo, então eu acho fantástico (E4).

A GT facilita junto ao sujeito o processo de ficar aware daquilo que está fazendo consigo e com sua vida, ou seja, facilita o seu processo de se dar conta de si mesmo, de suas atitudes, do seu campo. À medida que o reconhecimento e a conscientização do sujeito vão acontecendo, este vai desenvolvendo um "autossuporte" para que possa tomar uma atitude diante daquilo que foi conscientizado. Outro aspecto importante da awareness é o aqui e agora, ou seja, a valorização do momento presente, pois, para a GT, só é possível existir no aqui-e-agora. Ainda que a pessoa traga fatos passados e expectativas futuras, o está fazendo no momento presente. O que importa é o significado que dá atualmente para passado e futuro. Ou seja, é somente no aqui-e-agora que pode estar consciente de si mesmo, suas necessidades e de seu campo, e se transformar de alguma forma, caso seja esse o seu desejo:

A questão de trabalhar, não com esse sujeito do passado... de viver em função de um inconsciente, de um sujeito viver preso a um passado... Na Gestalt a gente vê muito o presente... E aí, eu gosto muito é... do "para quê?" Porque ai vem a questão de você se descobrir... Esse para quê é o que a Gestalt vem trabalhar. Então, essa função que o sintoma tem, para essa pessoa (E4).

Outra forma de facilitar o processo de conscientização do sujeito, e que inclusive facilita também o diálogo, são os recursos corporais e artísticos que a GT utiliza, pela sua dimensão terapêutica:

A gente procura trabalhar com o que emerge, tentar vivenciar aquele momento, fazer atividades mais vivenciais... levar atividades que envolvem mais o paciente, trabalhar mais com o aqui-e-agora, com aquilo que emerge... pode fazer exercício de respiração, de relaxamento... ou alguma atividade no papel, desenho... que eles possam a falar o que está emergindo, o que estão sentido naquele momento (E11).

Exercícios de respiração e relaxamento propiciam a conscientização da pessoa sobre seu corpo, suas dores e sensações, e sobre a própria situação de vida. A partir disso, a pessoa pode fazer pontes dentro do seu processo saúde-doença. Nas atividades artísticas, o foco deve ser voltado para as possibilidades de conexão entre a produção artística e o processo de conscientização. Desenhos, colagens, pinturas, dentre outros recursos, ajudam a perceber sentimentos antes não percebidos, e dar novos significados a relações e situações conflituosas, de modo que o sujeito encontra outras formas de lidar com estas situações e relações (Kiyan, 2009).

Assim, o psicólogo que, por meio dos recursos interventivos mais adequados para cada situação, facilita a tomada de consciência do sujeito sobre seu momento atual de vida e sua responsabilidade sobre isso está contribuindo com a conscientização e autonomia propostas pela ESF, constituindo-se em mais uma contribuição articuladora da GT para a atuação deste profissional neste contexto do Sistema Único de Saúde (SUS).

\section{Conexões teóricas e práticas da formação profissional do psicólogo}

Quando o psicólogo compreende que território e comunidade fazem parte da vida dos sujeitos e influenciam diretamente no seu processo saúde-doença, surge a sua percepção sobre as necessidades desses sujeitos que funcionam como uma totalidade e que, numa relação dialógica, tomam consciência de seu contexto de vida e do que podem fazer por ele mesmo. É dessa forma que a integralidade e a corresponsabilidade propostas pela ESF podem ser colocadas em prática.

Considerando a saúde como um processo coletivo, que envolve uma atitude ativa dos diversos sujeitos que se relacionam e estão implicados no contexto da ESF, diante das dificuldades enfrentadas nas suas dimensões orgânica, psíquica, e social, o trabalho do psicólogo passa pela tentativa de, por meio de uma relação de confiança, facilitar um processo de refazer sentidos e projetos de vida, permitindo a apropriação do sujeito sobre a sua singularidade e totalidade (Pretto et al., 2009).

O alinhamento teórico entre as diversas correntes de formação, portanto, é imprescindível para que o psicólogo possa atuar na direção da ampliação da saúde, tornando seu olhar e escuta mais integral. 
Ou seja, compreender que articulados, como numa "fusão de perspectivas", esses referenciais teóricos, políticos, filosóficos e metodológicos darão ao psicólogo um essencial e mais abrangente suporte para o seu fazer no contexto da ESF, sendo mais adequado pensar na aproximação do que na separação das diversas perspectivas téorico-práticas de formação:

Eu não sei se a gente chama assim, o Humanismo enquanto abordagem, a Fenomenologia enquanto Filosofia e a Psicologia Social enquanto área de atuação, mas tudo isso junto, sem dúvida, me faz uma boa psicóloga na Saúde da Família (E3).

Abordagens psicológicas e seus campos de atuação podem e precisam andar juntos, não havendo necessidade de separação, inclusive porque elas podem ser complementares. Pela diversidade e complexidade encontradas nos campos de atuação da Psicologia, é necessário que as fundamentações teóricas forneçam suporte nas suas diversas dimensões. Para um psicólogo realizar seu trabalho com qualidade, é essencial que, ao entrar numa determinada área de atuação, busque se apoiar numa abordagem que tenha bases filosóficas e metodológicas que façam sentido para ele naquele contexto.

Assim, podemos concluir que a Psicologia ao longo dos últimos anos vem ampliando seu campo de atuação, o que fez com que o psicólogo passasse a ser requisitado em diversas novasáreas. Diante dessa diversidade de áreas de atuação e embasamentos teórico-metodológicos, cabe ao profissional atuante ter uma visão multifacetada, para atender às demandas do tipo de atuação profissional onde está inserido e ampliar cada vez mais estes espaços de forma qualificada (Souza, \& Souza, 2012).

\section{Conexões teóricas e práticas da Gestalt-terapia, da Clínica Ampliada e da Estratégia Saúde da Família na atuação do psicólogo no SUS}

Pensando em conexões teóricas entre ESF, CA e GT, é possível aproximar Integralidade, Sujeito Singular e Totalidade, sugerindo que na medida em que o psicólogo trabalha de uma maneira integral com um sujeito, que é compreendido enquanto singular (individual ou coletivo), necessitará olhar para aquele sujeito enquanto uma totalidade. Os conceitos de forças externas e internas, comunidade e território, processo saúde-doença, necessidades sociais e de saúde, campo, ajustamento criativo e figura e fundo também podem ser aproximados, uma vez que as forças externas e internas, as quais estão o tempo todo interagindo com o sujeito singular, se dão dentro de um campo, onde comunidade e território se configuram. As mesmas forças estão interferindo no processo saúde-doença do sujeito singular e fazendo com que ele se ajuste da melhor forma possível dentro do seu campo. Ainda essas mesmas forças fazem emergir desse sujeito necessidades de diversas dimensões, que se organizam de modo que vão sendo satisfeitas - e assim deixando de ser figuras e se alocando num fundo - para que outras figuras possam emergir do fundo e também serem satisfeitas, caracterizando assim um ciclo de vida saudável.

Os conceitos de vínculo, conscientização, coprodução dialética, relação dialógica e awareness podem se aproximar quando à medida que dois sujeitos singulares se encontram, se constroem e se produzem reciprocamente, influenciando e sendo influenciado pelas próprias forças e pelas do outro, o vínculo entre eles vai sendo desenvolvido, pois surge de uma relação baseada no diálogo genuíno e aberto, que vai facilitar um processo de conscientização desses sujeitos sobre si mesmos e sobre os outros e seu mundo. O olhar gestáltico possibilita perceber que a coexistência de responsabilidades e o vínculo podem ser construídos a partir da relação dialógica, a qual se refere à atitude relacional do ser humano que ocorre através do diálogo construído a partir do encontro entre profissional e pessoa, família ou comunidade.

Do ponto de vista da Clínica Ampliada, é possível pensar no encontro entre dois sujeitos singulares, cada um com seu modo de ser e estar naquele momento e com seu papel no CSF: o profissional que conhece a técnica e a doença de forma geral, e o usuário que conhece a doença que está no seu corpo e/ou na sua alma. Nesse encontro entre dois inteiros singulares, ambos necessitam um do outro para que aquela doença seja compreendida e tratada também de forma singular. Quando olhares se encontram e se conectam, a saúde pode ser ampliada.

\section{Considerações finais}

Em atendimentos individuais ou atividades de grupo, foi percebido que a maior parte dos psicólogos entrevistados utiliza-se das abordagens psicológicas, e principalmente de base humanista, onde a GT está inserida. Inclusive, parte dos participantes refere utilizar especificamente da abordagem gestáltica. Partindo da premissa de que a abordagem utilizada com um sujeito tendo como foco sua necessidade atual, inde- 
pendente da teoria que a fundamenta, é um modo de compreendê-lo como um todo, foi possível observar no material empírico estudado que o conceito de totalidade está presente na prática dos psicólogos dentro da ESF, pois todos os entrevistados relataram intervenções que partiam sempre das demandas que indivíduos ou coletivos expressavam, e só depois da sua compreensão, essas intervenções eram postas em prática.

Quando uma abordagem psicológica possui uma visão de mundo e de homem que se aproxima das diretrizes da ESF, e o psicólogo consegue unir ambos os saberes e práticas, a atuação qualificada neste contexto, tão complexo como o da ESF, é mais facilitada. As convicções que a GT possui do homem como um ser de possibilidades, dignidade, confiança são também contribuições para o trabalho do psicólogo na ESF, uma vez que fortalece as intervenções direcionadas para a autonomia, cidadania, e conscientização dos sujeitos. Dessa forma, pode-se

\section{Referências}

Andrade, L. O. M., Barreto, I. C. H. C., \& Bezerra, R. C. (2009). Atenção primária à saúde e estratégia saúde da família. In G. W. S. Campos, Y. M. Carvalho, M. C. S. Minayo, M. Drumond Junior, \& M. Akerman, Tratado de saúde coletiva (pp. 783-836). Rio de Janeiro: Fiocruz.

Bastos, A. V. B., \& Gomide, P. I. C. (1989). O psicólogo brasileiro: sua atuação e formação profissional. Psicologia: Ciência e Profissão, 9(1): 6-15. doi:10.1590/S1414-98931989000100003

Brasil (2009). Ministério da Saúde. Saúde na escola (Série B - Textos básicos de saúde. Cadernos de Atenção Básica, n. 27). Brasília, DF: o autor.

Camargo-Borges, C., \& Cardoso, C. L. (2005). A psicologia e a estratégia saúde da família: compondo saberese fazeres. Psicologiae Sociedade, 17(2):26-32. doi:10.1590/S0102-71822005000200005

Campos, G. W. S. (2009). Clínica e saúde coletiva compartilhadas: Teoria Paidéia e reformulação ampliada do trabalho em saúde. In G. W. S. Campos, Y. M. Carvalho, M. C. S. Minayo, M. Drumond Junior, \& M. Akerman, Tratado de saúde coletiva (pp. 41-80). Rio de Janeiro: Fiocruz.

Ceccim, R. B. (2005). Educação permanente em saúde: desafio ambicioso e necessário. Interface - Comunicação, Saúde e Educação, 9(16): 161-77. refletir sobre o psicólogo enquanto seu próprio instrumento de trabalho, pois a relação a ser estabelecida com esses sujeitos, os vínculos e afetos a serem desenvolvidos e o modo de intervenção a ser utilizado no seu processo saúde-doença fazem parte do escopo da sua responsabilidade.

Pensando nas contribuições conceituais, filosóficas e metodológicas da GT, é possível estender tais contribuições para os outros profissionais de saúde, caso se identifiquem com uma visão de homem que é um todo unificado e integrado, responsável pelas escolhas de sua vida, capaz de se transformar e se reinventar em busca da sua saúde. É importante deixar claro que a intenção desse trabalho é mostrar as contribuições da Gestalt-terapia para a atuação do psicólogo na ESF, não havendo intuito algum em desqualificar ou excluir as outras abordagens deste contexto, uma vez que todas e cada uma delas tem o seu valor e relevância, diante de cada situação singular.

Ceccim, R. B. (2010). Residências em saúde: as muitas faces de uma especialização em área profissional integrada ao SUS. In: Fajardo, A. P., Rocha, C. M. F, \& Pasini, V.L. (Orgs.), Residências em saúde:fazeres \& saberes na formação em saúde. Porto Alegre: Hospital Nossa Senhora da Conceição.

Ceccim, R. B., \& Feuerwerker, L. C. M. (2004). O quadrilátero da formação para a área da saúde: ensino, gestão, atenção e controle social. Physis, 14(1): 41-65.

Conselho Federal de Psicologia (2009). A prática da psicologia e o núcleo de apoio à saúde da família. Brasília, DF: o autor.

Cordioli, A. V. (1998). Psicoterapias: abordagens atuais. Porto Alegre: Artmed.

Cunha, G. T. (2010). A construção da clínica ampliada na atenção básica (3a ed). São Paulo: Hucitec.

D’Acri, G., Lima, P., \& Orgler, S. (2007). Dicionário de Gestalt-terapia. São Paulo: Summus.

Frazão, L. M., \& Fukumitsu, K. O. (Org.) (2014). Gestalt-terapia: conceitos fundamentais (Coleção Gestalt-terapia: fundamentos e práticas, 2). São Paulo: Summus.

Gil, C. R. R. (2005). Formação de recursos humanos em saúde da família: paradoxos e perspectivas. Caderno de Saúde Pública, 21(2): 490-498. doi:10.1590/ S0102-311X2005000200015

Gois, C.W. L. (2005). Psicologia comunitária: atividade e consciência. Fortaleza: Instituto Paulo Freire de Estudos Psicossociais. 
Gois, C. W. L. (2008). Saúde comunitária: pensar e fazer. São Paulo: Hucitec.

Kiyan, A. M. M. (2001). E a gestalt emerge: vida e obra de Frederick Perls. São Paulo: Altana.

Minayo, M. C. S. (2010). Odesafio do conhecimento: pesquisa qualitativa em saúde (12a ed.). São Paulo: Hucitec.

Minayo, M. C. S. (2012). Pesquisa social: teoria, método e criatividade. Petrópolis: Vozes.

Nepomuceno,L.B.\&Brandão,I.R. (2011).Psicólogosnaestratégia saúde da família: caminhos percorridos e desafios a superar. Psicologia: Ciência e Profissão, 31(4): 762-777. doi:10.1590/S1414-98932011000400008

Orgler, S., Lima, P., \& D’Acri, G. (Org.). (2007). Dicionário de Gestalt-terapia: “Gestaltês". São Paulo: Summus.

Pedrassoli, A. (2008). O que é psicologia. Recuperado de http://www.portaldapsique.com.br/Artigos/O_que_e_Psicologia.htm

Perls, F. (1981b). A abordagem gestáltica e a testemunha ocular da terapia (2a ed.). Rio de Janeiro: Zahar.

Perls, F. (1981a). Gestalt-terapia explicada. São Paulo: Summus.

Pretto,Z.,Langaro,F., \&Santo, G. B. (2009).Psicologiaclínica existencialista na Atenção Básica à Saúde: um re-

\section{Juliana Diógenes}

Psicóloga, Mestre em Saúde Pública, e Doutoranda em Saúde Coletiva, pela Universidade Federal do Ceará, Fortaleza-CE. Brasil.

E-mail: judiogenes.espce@yahoo.com.br

\section{Ricardo José Soares Pontes}

Docente da Universidade Federal do Ceará, Fortaleza - CE. Brasil. Doutor em Medicina Preventiva e Social pela Faculdade de Medicina de Ribeirão Preto-USP. E-mail: rjpontes@fortalnet.com.br lato de atuação. Psicologia: Cência e Profissão, 29(2): 394-405. doi:10.1590/S1414-98932009000200014

Ribeiro, J. P. (2006). Vade-mécum de Gestalt-terapia: conceitos básicos. São Paulo: Summus.

Ribeiro, J. P. (2012). Gestalt-terapia: refazendo um caminho (8a ed. rev.). São Paulo: Summus.

Ronzani, T. M., \& Rodrigues, M. C. (2006). O psicólogo na atenção primária à saúde: contribuições, desafios e redirecionamentos. Psicologia Cência e Profissão, 26(1): 132-143. doi:10.1590/S1414-98932006000100012

Santos, A. L., \& Rigotto, R. M. (2010) Território e territorialização: incorporando as relações produção, trabalho, ambiente e saúde na atenção básica à saúde. Trabalho, Educação e Saúde, 8(3): 387-406. doi:10.1590/S1981-77462010000300003

Souza, M. F., \& Souza, R. L. (2012). O processo de escolha da área de atuação pelo graduando de Psicologia. Revista Kaleidoscópio, 3: 36-58.

Yontef, G. M. (1998). Processo, diálogo e awareness: ensaios em Gestalt-terapia. São Paulo: Summus.

Zinker, J. (2007). Processo criativo em Gestalt-terapia. São Paulo: Summus.

\section{Endereço para envio de correspondência:}

Universidade Federal do Ceará, Faculdade de Medicina, Departamento de Saúde Comunitária, Rua Professor Costa Mendes, 1608, $5^{\circ}$ andar - Rodolfo Teófilo.

CEP: 60430140.

Fortaleza - CE. Brasil.

Recebido 14/02/2014

Aprovado 02/02/2016

Received 02/14/2014

Approved 02/02/2016

Recibido 14/02/2014

Aceptado 02/02/2016

Como citar: Diógenes, J., \& Pontes, R. J. S. (2016). A atuação do psicólogo na estratégia saúde da família: articulações teóricas e práticas do olhar gestáltico. Psicologia: Ciência e Profissão, 36(1): 158-170. doi:10.1590/1982-3703001702014

How to Cite: Diógenes, J., \& Pontes, R. J. S. (2016). The Performance of the Psychologist in the Family Health Strategy: Combining Theory and Gestalt-Oriented Practices. Psicologia: Ciência e Profissão, 36(1): 158-170. doi:10.1590/1982-3703001702014

Cómo citar: Diógenes, J., \& Pontes, R. J. S. (2016). La Actuación del Psicólogo en la Estrategia de Salud de la Familia: Teoría y Prácticas deVisión Gestáltica en Conjunto. Psicologia:Ciênciae Profissão,36(1): 158-170. doi:10.1590/1982-3703001702014 